\title{
Analyzing Doubly Fed Induction Generator Impact in an Electrical Grid
}

\author{
T.O. Ruben, H.T. Agustina, A.M. Omar, M.M. David \\ Department of Graduate Studies, Universidad Politécnica de Tulancingo, Tulancingo, Hidalgo, México, This work was supported \\ under Grant PROMEP Redes Temáticas de Colaboración
}

\begin{abstract}
This paper examines the reactive power control capability of doubly fed induction generator connecting to distribution grid with and without the inclusion of capacitor banks. The dynamic response characteristics of the wind power generator in the case of fault in the network to assure the secure and reliable operation of wind farm is presented. The stator-fluxoriented vector control principle is applied to build a model of the doubly fed induction generator in dq synchronous coordination system and the simulation software is employed to investigate its performance into distribution grid of eleven nodes.
\end{abstract}

Keywords- DFIG; distribution grid; reactive power

\section{INTRODUCTION}

Wind power may be considered one of the most promising renewable energy sources, but its integration into power systems has a number of technical challenges concerning security of supply, in terms of reliability, availability and power quality [1-3]. Since penetration of wind power generation is growing, its impact on the connected power system must be analyzed. For this reason, grid connection requirements are established. In the last few years, the connection requirements have incorporated in addition to steady state problems, dynamic requirements, like voltage dip ride-through capability $[4,5]$. The most common requirements under these disturbances are low voltage ride through which usually implies: voltage profile immunity, reactive current injection, active and reactive power limitation under fault and recovery and limitation in reactive energy consumption $[5,6]$. In the past, before a serious failure in the electrical grid, energy conversion systems (WECS) were disconnected. However, due its penetration has been increased it is necessary that all time must remain connected, since they provide a large amount of power [7]. The continuous operation under different perturbations is not easy to get, the control structure must ensure proper dynamic response. The major literature includes control structure to doubly fed induction generator (DFIG) connected to an infinite bus but does not contain all structure of the electrical grid $[1,8,9]$. Analyzing a control scheme with a suitable model system largely ensure proper operation in actual conditions. Therefore, a comprehensive study of the electrical grid including WECS with detail control structure considering the effect of major disturbances and the behavior of voltage and power flows is required.

\section{DFIG-BASED WIND TURBINES}

Fig. 1 shows the schematic diagram of DFIG-based wind generators. The DFIG is an induction machine with a wound rotor where the rotor and stator are both connected to electrical sources, hence the term "doubly- fed". The rotor has three phase windings energized with three-phase currents. These rotor currents establish the rotor magnetic field. The rotor and stator magnetic fields interact to developed torque. The magnitude of the torque depends on the strength of the two fields. The system ensures efficient power conversion due to variable rotor speed, which adjusts itself automatically in accordance with prevailing wind speeds. Speed variability is made possible by the directionally dependent transfer of slip power via the frequency converter, which changes as follows [10]: a) In the sub-synchronous operating mode (partial load range), the stator of the DFIG supplies power to the grid and also the slip power to the rotor via slip rings and frequency converter; b) In the super-synchronous operating mode (nominal load range), both, the stator output power and the rotor slip power are fed into the grid.

\section{CONTROL SCHEME}

\section{A. Grid side Converter Control}

The objective of grid-side converter is to keep the direct current (DC) link voltage constant regardless of the magnitude and direction of the rotor power. The vector-control method is used as well, with a reference frame oriented along the stator voltage vector position, enabling independent control of the active and reactive power flowing between the grid and converter. The converter is current regulated, with the d-axis current used to regulate the dc-link voltage and q-axis current component to regulate the reactive power. The voltage equations in synchronously rotating dq-axis reference frame are:

$$
\begin{gathered}
v_{c d}=R i_{c d}+L_{r} \frac{d i_{c d}}{d t}-\omega_{e} L_{r} i_{c q}+v_{c d 1} \\
v_{c q}=R i_{c q}+L_{r} \frac{d i_{c q}}{d t}+\omega_{e} L_{r} i_{c d}+v_{c q 1}
\end{gathered}
$$

The angular position of the grid voltage is calculated as,

$$
\theta_{e}=\int \omega_{e} d t=\tan ^{-1} \frac{v_{c \beta}}{v_{c \alpha}}
$$

where $\operatorname{vc} \alpha$ y $\operatorname{vc} \beta$ are the converter grid-side voltage stationary frame components. 


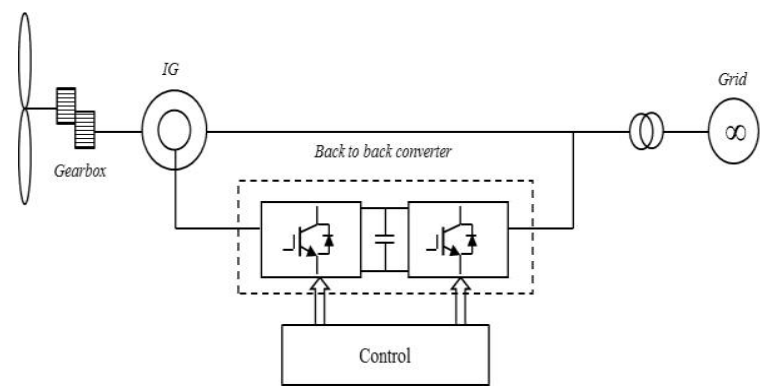

FIGURE I. SCHEMATIC DIAGRAM OF DFIG-BASED WIND GENERATORS.

The d-axis of the reference frame is aligned with the grid voltage angular position $\theta_{e}$. If voltage grid amplitude is constant, $v_{c q}$ is zero and $v_{c d}$ is constant. Active and reactive power will be proportional to $i_{c d}$ and $i_{c q}$, respectively. Assuming star connection on grid side transformer, converter active and reactive power flows are,

$$
\begin{aligned}
& P_{c}=3\left(v_{c d} i_{c d}+v_{c q} i_{c q}\right)=3 v_{c d} i_{c d} \\
& Q_{c}=3\left(v_{c d} i_{c q}+v_{c q} i_{c d}\right)=3 v_{c d} i_{c q}
\end{aligned}
$$

For the internal control loop it is necessary to design the proportional integral (PI) controller's parameters, which are obtained by application of Laplace Transform to (1) and (2) and represent the grid-side converter voltages in its dqcomponents. References for the voltages values $v_{c d}^{*}$ and $v_{c q}^{*}$ are [11]:

$$
\begin{aligned}
& v_{c d}^{*}=-v_{c d}^{\prime}+\left(\omega_{e} L_{r} i_{c q}+v_{c d}\right) \\
& v_{c q}^{*}=-v_{c q}^{\prime}-\left(\omega_{e} L_{r} i_{c d}\right)
\end{aligned}
$$

\section{B. Rotor Side Converter Control}

The first step for the rotor side converter control is to determine the instantaneous stator rotating flux vector location $\theta_{s}$.

$$
\left\{\begin{array}{l}
\psi_{s \alpha}=\int\left(v_{s \alpha}-R_{s} i_{s \alpha}\right) d t \\
\psi_{s \beta}=\int\left(v_{s \beta}-R_{s} i_{s \beta}\right) d t
\end{array}, \quad \theta_{s}=\tan ^{-1}\left(\frac{\psi_{s \beta}}{\psi_{s \alpha}}\right)\right.
$$

The next step is to generate the rotor current references. For this purpose two PI regulators with the inputs of $Q_{r e f}$ and $\omega_{r}$ are used, as shown in figure 2.

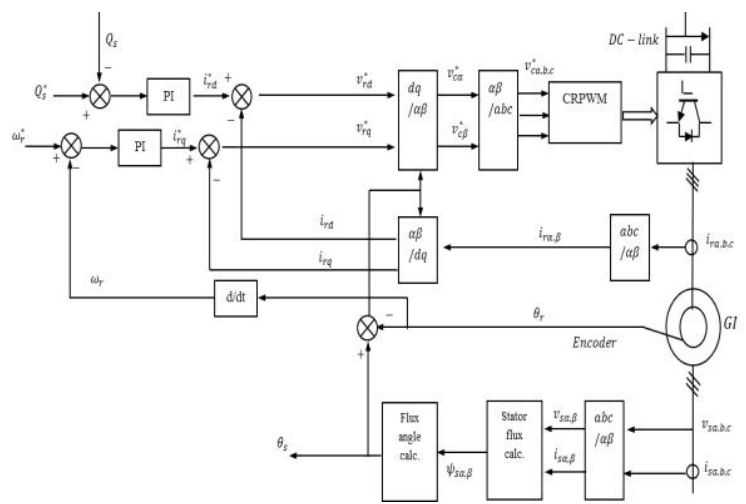

FIGURE II. CONTROL STRUCTURE FOR ROTOR SIDE CONVERTER.

\section{TEST RESULTS}

Fig. 3 shows the test utility network. It has 11 buses at 13.8 $\mathrm{kV}$ and 9 loads with total active and reactive ratings of 1.1475 MW and 0.7101 MVARs, respectively. There are two wind farms connected in nodes 7 and 10 through back to back converter with a control structure as shown in section 3 . In order to verify the control scheme of the DFIG in an electrical grid, the demand of active and reactive power and its capability to remain connected to the distribution grid with security is studied. Two cases are analyzed in the PSCAD software.

\section{A. Case 1}

It's presented the analysis of power flow solution with wind turbines into the distribution grid. The system is initially inactive; all variables are zero and after a transient period are stabilized around a constant value. The 9 loads are-150 kVA each one, i.e., the nominal capacity of the transformer with a power factor of 0.85 . Table 1 shows measurements for different wind speeds. Generation units should remain around unity power factor at the connection point due to the control scheme. The level of reactive power is controlled by the conversion system by assigning a reference value equal to zero. Turbines are operating with a power factor close to unity. Furthermore, the DFIG has the ability to regulate the reactive power flow exchanged with the grid in steady state at different wind speeds. The control structure guaranties such behavior.

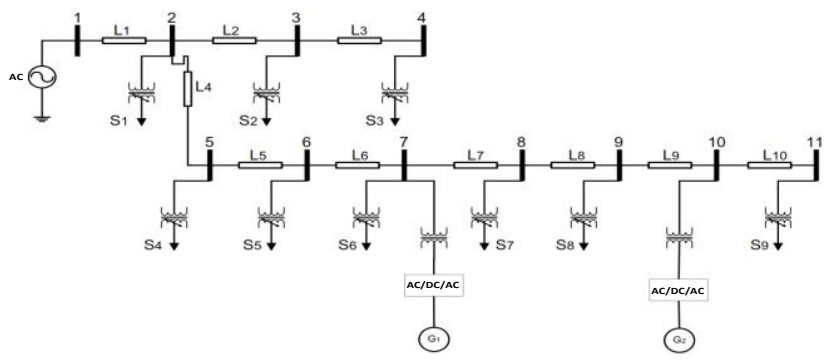

FIGURE III. SINGLE LINE DIAGRAM OF TEST ELECTRICAL GRID.

TABLE I. MEASUREMENT OF POWER FLOW AT EACH GENERATION UNIT.

\begin{tabular}{|l|l|l|l|l|l|l|}
\hline \multirow{2}{*}{$\begin{array}{c}\text { Wind } \\
\text { Speed } \\
\mathrm{m} / \mathrm{s}\end{array}$} & \multicolumn{3}{|c|}{ DFIG 1 } & \multicolumn{3}{c|}{ DFIG 2 } \\
\cline { 2 - 7 } & $\mathrm{P}_{1} M W$ & $\mathrm{Q}_{1} M V A r s$ & $\mathrm{PF}_{1}$ & $\mathrm{P}_{2} M W$ & $\mathrm{Q}_{2}$ MVArs & $\mathrm{PF}_{2}$ \\
\hline 6 & 0.169 & -0.017 & 0.99 & 0.173 & 0.003 & 0.99 \\
\hline 9 & 0.276 & 0.010 & 0.99 & 0.287 & 0.012 & 0.99 \\
\hline 12 & 0.568 & 0.0005 & 0.99 & 0.570 & 0.001 & 0.99 \\
\hline 15 & 1.205 & -0.079 & 0.99 & 1.253 & -0.054 & 0.99 \\
\hline
\end{tabular}

Though system's control has a good response, it operates with unity power factor and no reactive power exchange with the distribution network. Therefore, inclusion of a capacitor bank in the common connection point in order to cover the supply of reactive power demanded by system's elements to avoid problems of stability and improve voltage profile is examined. Comparison results with and without inclusion of capacitors banks are presented in table 2 . 
TABLE II. COMPARISON RESULTS WITH AND WITHOUT INCLUSION OF CAPACITORS BANKS.

\begin{tabular}{|c|c|c|c|c|c|c|c|}
\hline \multicolumn{2}{|c|}{ Line } & \multicolumn{3}{|c|}{ Without capacitors banks } & \multicolumn{3}{|c|}{ With capacitors banks } \\
\hline from & to & $\begin{array}{c}\mathrm{P} \\
M W \\
\end{array}$ & $\begin{array}{c}\mathrm{Q} \\
\text { MVArs }\end{array}$ & $\begin{array}{c}\mathrm{S} \\
M V A\end{array}$ & $\begin{array}{c}\mathrm{P} \\
M W\end{array}$ & $\begin{array}{c}\mathrm{Q} \\
\text { MVArs }\end{array}$ & $\begin{array}{c}\mathrm{S} \\
M V A\end{array}$ \\
\hline 1 & 2 & 0.037 & 0.779 & 0.779 & 0.0134 & -0.0102 & 0.016 \\
\hline 2 & 3 & 0.254 & 0.161 & 0.300 & 0.256 & 0.162 & 0.302 \\
\hline 2 & 5 & -0.357 & 0.516 & 0.627 & -0.371 & -0.254 & 0.449 \\
\hline 5 & 6 & -0.489 & 0.429 & 0.650 & -0.500 & -0.339 & 0.604 \\
\hline 6 & 7 & -0.618 & 0.344 & 0.707 & -0.632 & -0.423 & 0.760 \\
\hline G1 & 7 & 0.566 & 0.0002 & 0.566 & 0.574 & 0.377 & 0.686 \\
\hline 7 & 8 & -0.183 & 0.256 & 0.314 & -0.190 & -0.134 & 0.232 \\
\hline 8 & 9 & -0.310 & 0.177 & 0.356 & -0.319 & -0.217 & 0.385 \\
\hline 9 & 10 & -0.438 & 0.094 & 0.447 & -0.450 & -0.302 & 0.541 \\
\hline G2 & 10 & 0.570 & -0.0007 & 0.570 & 0.583 & 0.391 & 0.701 \\
\hline 10 & 11 & 0.126 & 0.079 & 0.148 & 0.128 & 0.081 & 0.151 \\
\hline 2 & 1 & -0.016 & -0.753 & 0.753 & -0.013 & 0.0107 & 0.017 \\
\hline 3 & 2 & -0.254 & -0.160 & 0.300 & -0.255 & -0.161 & 0.301 \\
\hline 5 & 2 & 0.370 & -0.504 & 0.625 & 0.373 & 0.258 & 0.453 \\
\hline 6 & 5 & 0.500 & -0.419 & 0.652 & 0.503 & 0.342 & 0.608 \\
\hline 7 & 6 & 0.631 & -0.333 & 0.713 & 0.631 & 0.425 & 0.760 \\
\hline
\end{tabular}

Total demand of active and reactive power is $1.1475 \mathrm{MW}$ and 0.7101 MVARs, respectively. The total active power generated without the inclusion of the capacitor bank is 1.173 MW and the reactive power is 0.7785 MVARs. Table 2 shows that without capacitors banks the active power demand is supplied in $98.99 \%$ by wind turbines, while $1.01 \%$ is cover by the alternate current (AC) grid. Reactive power results are different: $100 \%$ of reactive power demanded is taken from the conventional AC network, hence the importance to include the capacitors banks to compensate reactive demand. Losses in the network decrease with integration of capacitor banks from 68.4 kVARs to $57.9 \mathrm{kVARs}$ and $10.2 \mathrm{kVARs}$ supplied to AC system. Also, voltage profile is better with capacitors banks inclusion and phase angles maintain closer to each other.

TABLE III. MAGNITUDE AND PHASE ANGLE OF NODAL VOLTAGES.

\begin{tabular}{|c|c|c|c|c|}
\hline \multirow{2}{*}{ Node } & \multicolumn{2}{|c|}{ Without capacitors banks } & \multicolumn{2}{c|}{ With capacitors banks } \\
\cline { 2 - 5 } & $\begin{array}{c}\text { Voltage } \\
(\mathrm{pu})\end{array}$ & $\begin{array}{c}\text { Phase } \\
\text { (degrees) }\end{array}$ & $\begin{array}{c}\text { Voltage } \\
(\mathrm{pu})\end{array}$ & $\begin{array}{c}\text { Phase } \\
(\text { degrees })\end{array}$ \\
\hline 1 & 1.0 & 0.0 & 1.0 & 0.0 \\
\hline 2 & 0.97 & 0.9799 & 0.99 & -0.08 \\
\hline 3 & 0.97 & 0.892 & 0.99 & -0.168 \\
\hline 4 & 0.97 & 0.87 & 0.99 & -0.190 \\
\hline 5 & 0.97 & 1.71 & 1.0 & 0.107 \\
\hline 6 & 0.97 & 2.18 & 1.01 & 0.266 \\
\hline
\end{tabular}

\section{B. Case 2}

It analyzes the behavior of DFIG in face of voltage drop across the network considering wind speed of $12 \mathrm{~m} / \mathrm{s}$. Reactive power control is regulate by side source converter. The system is subjected to a 3-phase short-circuit fault at bus 9, cleared after $10 \mathrm{~ms}$. At $\mathrm{t}=0.2 \mathrm{~s}$ the voltage at $\mathrm{G}_{1}$ terminals has decreased about $50 \%$ of its nominal value, while active and reactive powers present a transient period and reach steady state values, as shown in figure. 4 . For G2, reduction in voltage is about $65 \%$ of the nominal value and power returns to its steady-state value after $0.08 \mathrm{~ms}$. Results exhibit a good control structure performance.

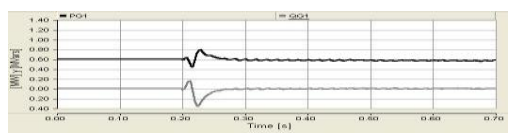

FIGURE IV. G1 WITH SHORT CIRCUIT FAULT, $10 \mathrm{MS}$ AT T $=0.2 \mathrm{~S}$ : ACTIVE AND REACTIVE POWER.

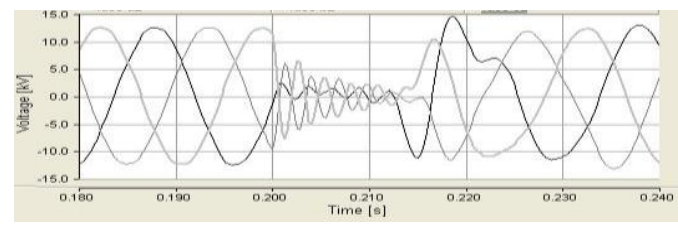

FIGURE V. 3-PHASE VOLTAGE AT CONNECTION NODE. FAULT AT $\mathrm{T}=0.2 \mathrm{~S}:$ G2 UNIT

The impact of the voltage drop at each generator depends on the proximity to the fault. For this study the fault is located closer to G2. Fig. 5 presents voltage behavior in the three phases at connection point for each wind turbine. The terminal voltage of $G_{2}$ during fault is lower than $G_{1}$, at $t=0.210 \mathrm{~s}$ the fault is cleared. The units tend to stabilize, and at $t=0.220 \mathrm{~s}$ attain its steady state value. Control structure adequately fulfilling its task with transient response when hard perturbations in the electrical grid are presented. Losses present in case 1 are smaller with inclusion of the capacitor bank. Another important aspect is the stability analysis of DFIG connected to network in face to voltage dips. The results show that the controller has a fast response and allows wind turbines successfully get over after the fault period and return to their steady state condition.

\section{REFERENCES}

[1] Soliman M., Malik O.P., Westwick D.T., Multiple Model Predictive Control for Wind Turbines With Doubly Fed Induction Generators. IEEE Trans. on Sustainable Energy, 2(3), pp. 215-225, 2011.

[2] Nguyen H.M., Subbaram Naidu, Advanced Control Strategies for Wind Energy Systems: An Overview. Proc. of the IEEE Power Engineering Society Power Systems Conference, pp. 1-8, 2011.

[3] Zamani M.H., Riahy G.H., Foroushani R.Z., Introduction of a new index for evaluating the effect of wind dynamics on the power of variable speed wind turbines. Proc. of the IEEE Power Engineering Society Transmission and Distribution Conference, pp. 1-6, 2008.

[4] Ghofrani M., Arabali A., Etezadi-Amoli M., Baghzouz Y., Operating reserve requirements in a power system with dispersed wind generation. Proc. of the IEEE Power Engineering Society Innovative Smart Grid Technologies, pp. 1-8, 2012.

[5] Rahmann C., Haubrich H.J., Moser A., Palma-Behnke R., Vargas L., Salles M.B.C. Justified Fault-Ride-Through Requirements for Wind Turbines in Power Systems. IEEE Trans. on Power Systems, 26(3), pp. 1555-1563, 2011.

[6] Hua Geng, Cong Liu, Geng Yang, LVRT Capability of DFIG-Based WECS Under Asymmetrical Grid Fault Condition. IEEE Trans. on Industrial Electronics, 60(6), pp. 2495-2509, 2013.

[7] Vinothkumar K., Selvan M.P., Novel scheme for enhancement of fault ride-through capability of doubly fed induction generator based wind farms. Energy Conversion and Management, 52(7), pp. 2651-2658, 2011.

[8] Van-Tung Phan, Hong-Hee Lee, Performance Enhancement of StandAlone DFIG Systems With Control of Rotor and Load Side Converters Using Resonant Controllers. IEEE Trans. on Industry Applications, 48(1), pp. 199-210, 2012.

[9] Hu J., Nian H., Hu B., He Y., Zhu Z.Q., Direct active and reactive power regulation of DFIG using sliding-mode control approach. IEEE Trans. on Energy Conversion, 25(4), pp. 1028-1039, 2010.

[10] Abad G., López J., Rodríguez M., Marroyo L., Iwanski G., Doubly Fed Induction Machine, (Chapter 9), IEEE Press, 2011.

[11] Pena R., Clare J.C., Asher G.M., Doubly fed induction generator using back-to-back PWM converters and its application to variable-speed wind-energy generation. IEE Proceedings Electric Power Applications, 143(3), pp. 231-241, 1996. 